\title{
Chlorpromazine-induced haemolytic anaemia in anorexia nervosa
}

\author{
J. How \\ M.B., Ch.B., M.R.C.P. \\ R. J. L. Davidson \\ M.D., F.R.C.P., M.R.C.Path. \\ Haematology Unit, Department of Pathology, University of Aberdeen, Foresterhill, \\ Aberdeen AB9 2ZD
}

\begin{abstract}
Summary
Two patients with anorexia nervosa who developed progressive haemolytic anaemia during chlorpromazine therapy are presented. In each case, withdrawal of the drug alone led to a prompt haematological response. Drug-induced oxidant damage is proposed as being the underlying haemolytic mechanism.

\section{Introduction}

Agranulocytosis is the most commonly recognized haematologieal complication of chlorpromazine therapy (Hartl, 1973). Haemolytic anaemia, on the other hand, is a rare event and to the authors' knowledge has been reported on only three previous occasions (Cooperberg and Eidlow, 1956; Lindberg and Norden, 1961; Hadnagy, 1976). The purpose of this communication is to describe two further cases and to propose a mechanism of the underlying haemolysis.
\end{abstract}

\section{Case 1}

An emaciated 20-year-old girl, weighing only 32.5 $\mathrm{kg}$, was admitted with the classical features of anorexia nervosa. Laboratory investigations on admission: Hb $11.0 \mathrm{~g} / \mathrm{dl}$; PCV 33\%; MCHC $34 \%$; WBC $2.7 \times 10^{9} / 1$ (39\% neutrophils, $60 \%$ lymphocytes, $1 \%$ monocytes) and reticulocytes $<1 \%$. Bone marrow examination showed moderate panhypoplasia. Erythropoiesis was of normoblastic type. Serum vitamin $B_{12}$ and folate levels were $>1000$ $\mathrm{ng} / \mathrm{l}$ and $>20 \mu \mathrm{g} / \mathrm{l}$ respectively. Serum proteins, urea, electrolytes and protein bound iodine were normal.

The patient was treated with a 3000 calorie diet, a multivitamin preparation (Multivite) and oral chlorpromazine, $100 \mathrm{mg}$ t.i.d. Serial blood examinations showed a gradual fall in haemoglobin to $8.8 \mathrm{~g} / \mathrm{dl}$ by the eighteenth day of treatment. This was accompanied by a rising reticulocyte response (Fig. 1), the appearance of a small population of pyknocytes and an occasional late normoblast in the peripheral blood film. During this period of observation neutrophils ranged from 1.6 to $2.4 \times 10^{9} / 1$ and platelets from 170 to $200 \times 10^{9} / 1$. There was no obvious source of blood loss and barium meal examination was normal. Serial faecal occult blood,
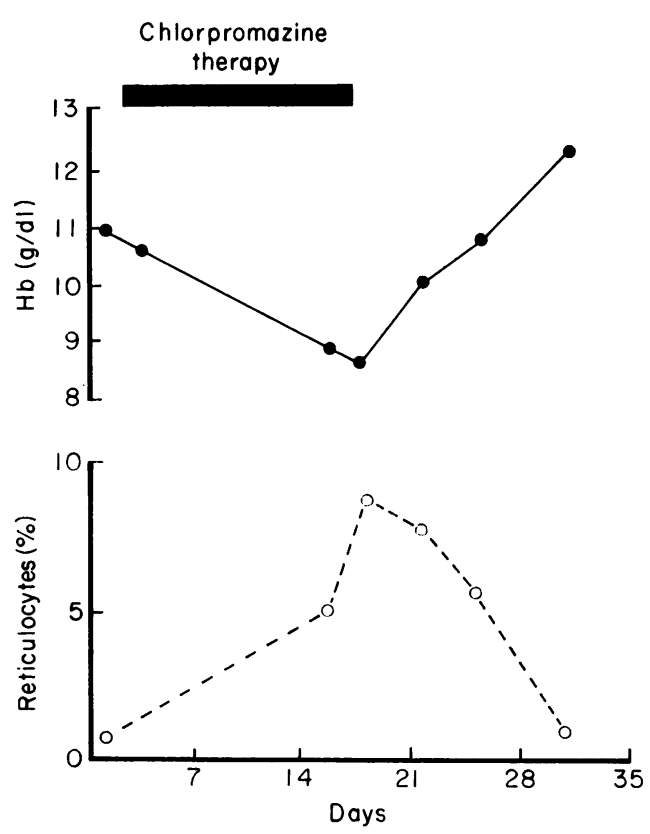

FIG. I.

antinuclear factor, direct antiglobulin, and Heinz body tests were negative. Serum bilirubin rose to $10.3 \mu \mathrm{mol} / 1$ from $3.4 \mu \mathrm{mol} / \mathrm{l}$ on admission and serial urine testing revealed increased urobilinogen. As the findings suggested the possibility of a drug-induced haemolytic process, treatment with chlorpromazine was discontinued and within 10 days the haemoglobin had almost returned to its pretreatment level. Her subsequent clinical course was uneventful and within 1 month she was discharged on no drug therapy. Follow-up blood examinations have remained normal.

\section{Case 2}

A 15 -year-old girl, weighing only $28 \mathrm{~kg}$, was admitted to hospital with severe anorexia nervosa that had developed insidiously over the previous 2 years. Laboratory investigations on admission: $\mathrm{Hb} 11.9$ g/dl, PCV 34\%, MCHC 35\%, WBC 3.8 × 10\% $/ 1$ (59\% neutrophils, $36 \%$ lymphocytes, $3 \%$ monocytes, $2 \%$ 
basophils), reticulocytes $<1 \%$ and platelets $197 \times$ $10^{9} / 1$. Tests of liver function, serum vitamin $B_{12}$, folate and electrolytes were normal, apart from a transient elevation of the urea to $13.7 \mathrm{mmol} / \mathrm{l}$.

The patient was treated with a multivitamin preparation (Vitavel) and oral chlorpromazine, $100 \mathrm{mg}$ q.i.d. Serial blood examinations again showed a progressive fall in haemoglobin from 11.9 to $9.5 \mathrm{~g} / \mathrm{dl}$ and an accompanying reticulocytosis which had reached $18 \%$ by the seventeenth day of treatment, when the drug was stopped. During this period, red cell pyknocytosis was observed and supravital staining revealed numerous Heinz bodies. No methaemoglobinaemia was detected, the direct antiglobulin test was negative and glucose 6-phosphate dehydrogenase screening showed normal activity. Tests of liver function, platelets, white cell count and distribution remained normal. Within 14 days of withdrawing chlorpromazine, the haemoglobin and reticulocyte counts had returned to their pre-treatment levels and Heinz bodies were no longer detectable in the peripheral blood.

\section{Discussion}

The clinical and haematological findings in these two patients strongly support a causal relationship between the haemolytic anaemia and the administration of chlorpromazine. In the previously reported cases, the mechanism of haemolysis has been variously explained. Thus, in one, the anaemia followed the cessation of chlorpromazine therapy and was associated with spherocytosis and a negative antiglobulin test (Cooperberg and Eidlow, 1956). Lindberg and Norden (1961) described a patient in whom acute haemolysis and haemoglobinuria followed the intravenous administration of a single dose of chlorpromazine $(25 \mathrm{mg})$ and postulated a drug-dependent immune mechanism. More recently, Hadnagy (1976) reported a direct Coombs-positive haemolytic anaemia in an alcoholic patient who for 10 years had taken a hypnotic mixture containing chlorpromazine. The mechanism of haemolysis in the two cases reported here, however, does not appear to have an immune basis. The red cell pyknocytosis and the presence of Heinz bodies observed in case 2, suggest a direct 'toxic' effect, possibly of an oxidative nature, on the red cells. This view gains support from the demonstration of haemolysis by chlorpromazine in vitro (Freeman and Spirtes, 1962) and the fact that the haemolytic anaemia associated with thiodiphenylamine therapy is dose-related (Dacie, 1967).

In addition, the authors have personal knowledge of a third patient with anorexia nervosa who, following 21 days' treatment with chlorpromazine, $150 \mathrm{mg}$ daily, developed a severe normochromic anaemia (Hb $6.9 \mathrm{~g} / \mathrm{dl}$ ) accompanied by a reticulocytosis. An association with chlorpromazine therapy was suspected and following its withdrawal, the haemoglobin rose to $10 \cdot 1 \mathrm{~g} / \mathrm{dl}$ within 3 weeks.

The striking red cell changes observed in these three patients are in marked contrast to the mild anaemia and reticulocytopenia usually found in anorexia nervosa (Mant and Faragher, 1972). However, minor degrees of drug-induced haemolysis may not only remain unsuspected but mild anaemia may be wrongly attributed to the underlying anorexia nervosa. Finally, the recognition of haemolysis is of importance as withdrawal of the drug would appear to be followed by an immediate haematological response.

\section{Acknowledgments}

We thank Professor W. M. Millar and Drs M. J. Williams and J. K. Morrice for allowing us to publish details of patients under their care.

\section{References}

Cooperberg, A.A. \& Eidlow, S. (1956) Hemolytic anemia, jaundice and diabetes mellitus following chlorpromazine therapy. Canadian Medical Association Journal, 75, 746.

DACIE, J.V. (1967) The Haemolytic Anaemias Part IV, 2nd edn, p. 1039. J. \& A. Churchill, London.

Freeman, A.R. \& SPIRTES, M.A. (1962) Effect of some phenothiazine derivatives on the haemolysis of red blood cells in vitro. Biochemical Pharmacology, 11, 161.

HadNaGY, C. (1976) Coombs-positive haemolytic anaemia provoked by chlorpromazine. Lancet, i, 423.

HARTL, P.W. (1973) Drug induced agranulocytosis. In: Blood Disorders Due to Drugs and Other Agents (Ed. by R. H. Girdwood), p. 157. Excerpta Medica, Amsterdam. Lindberg, L.G. \& Norden, A. (1961) Severe haemolytic reaction to chlorpromazine. Acta medica scandinavica, 170, 195.

MANT, M.J. \& FARAgher, B.S. (1972) The haematology of anorexia nervosa. British Journal of Haematology, 23, 737. 